\title{
SUSTAINING BEHAVIOUR CHANGE THROUGH IMMERSIVE TECHNOLOGIES: TRENDS, PERSPECTIVES, AND APPROACHES
}

\author{
Wittmann, Maximilian; \\ Cash, Philip; \\ Mariani, Milton; \\ Maier, Anja; \\ Hansen, John Paulin
}

DTU

\begin{abstract}
Long-term behaviour changes are critical to answering societal and individual challenges surrounding areas such as sustainability and health. Current understanding of how to bring about sustained behaviour is focused on the identification of Behaviour Change Techniques (BCTs) without explicit guidance on how these should be matched with technological solutions. Based on this gap we set out to answer the research question: What is the relationship between BCTs and interactive immersive technologies with respect to long-term, sustainable behaviour? To this end, we report a literature review on technology trends in the fields of human computer interaction, human robot interaction, and game design. Based on this review we develop three main contributions with implications for design theory and practice. First, we propose a number of characteristics and mechanisms in emerging immersive technologies. Second, we highlight technological pathways connected to specific BCT clusters likely to be disrupted: technology as a conveyor of information, an augmenter of feedback, and as an embodiment of empathy. Third, we explore these connections between BCT clusters and the actual technological interventions.
\end{abstract}

Keywords: Design for interfaces, Human behaviour in design, Virtual reality, Long-term Adherence, Healthcare Technology

\section{Contact:}

Cash, Philip

DTU Technical University of Denmark

DTU Management

Denmark

pcas@dtu.dk 


\section{INTRODUCTION}

Long-term or sustained behaviour changes is critical to answering societal and individual challenges surrounding areas such as sustainability and health. For example, the benefits of reduced energy consumption can only be achieved if individuals adopt and maintain long-term energy-saving behaviours (Sony and Mekoth, 2018). Similarly, in healthcare, adherence to a rehabilitation regime for people with neurological diseases (e.g. stroke patients) is critical. However, adherence rates decline in most patients after being discharged from hospital (Yao et al., 2017). In these contexts, emerging interactive immersive technologies, have the potential to support sustained behaviour change. Nonetheless, little is known regarding the design of immersive technologies in relation to sustaining behaviour over the longer term.

In order to address this challenge, designers need to both deal with the fundamentals of behaviour change and their embodiment in technology (Fogg, 2009a; Kelders et al., 2012). Yet, current understanding of how to bring about sustained behaviour is focused on the identification of Behaviour Change Techniques (BCTs) (Michie et al., 2013) with little explicit guidance on how these should be matched with technological solutions. Behavioural design, aiming to replace an undesired behaviour with a desired one with the help of interventions (Cash et al., 2017), draws a relationship between the design of technological and behavioural outcomes (Khadilkar and Cash, 2020). However, despite recent work by Cash et al. (2020) linking technological considerations to behavioural solutions, little is known about the specific dependencies and interactions between common BCTs and immersive technologies.

Given this need, we aim to answer the following research question: What is the relationship between BCTs and immersive technologies with respect to sustaining behaviour over the longer term? To do this we report a comparative review of emerging technology trends and current understanding of major long-term relevant Behaviour Change Techniques (BCT).

\section{THEORETICAL FRAMEWORK}

Behavioural design aims to replace undesired behaviours with desired behaviours through interventions (Cash et al., 2020). Tromp et al. (2011) emphasise that behavioural design comprises persuading, nudging, evoking, and motivating human beings to engage in a desired behaviour and bring about positive change. The previously mentioned interventions for behaviour change include e.g. the design of artefacts, (technical) systems, services, and campaigns (Khadilkar and Cash, 2020). Thus, behavioural design serves as a connector between behaviour change and technology.

Behaviour change is complex and needs to be approached systematically (Fogg and Hreha, 2010). For example, Fogg (2009b) differentiates behaviour change based on the familiarity of an individual with the intended new behaviour, the schedule, the intensity, the duration, and the frequency; which must all be addressed by matching motivations, enablers, and triggers (Fogg, 2009b). One recognised way of dealing with this complexity is by drawing on fundamental behaviour change mechanisms, with one of the most widely known frameworks being the Behaviour Change Technique Taxonomy (BCTT) presented by Michie et al. (2013). Here, Behaviour Change Techniques (BCT) are characterised as the "active ingredients within an intervention that lead to behaviour change" (Bohlen et al., 2020). These might include, for example, feedback, self-monitoring, or reinforcement. BCTs can be applied to alter causal processes regulating a behaviour in a wide area: from increasing physical activity and encouraging healthy eating, safe drinking or quit smoking, or even to changing professional behaviours (Michie et al., 2013). Such a set of BCTs provide a foundation for evaluating design directions as well as more specific technological solutions (Cash et al., 2020).

In the context of behaviour change, technologies influence people and can transform their behaviour. The last decades have seen a remarkable increase in technology-enabled interventions reflecting the advances in communication and information technologies (Janevic and Connell, 2019). These include deliveries of interventions via mobile devices (mHealth), apps, via the Internet (eHealth) or wearable systems (Naslund et al., 2017; Thorpe et al., 2016, 2019). The design of technology-enabled interventions often makes use of digital components incorporating elements such as apps, GPS, cameras, accelerometers, and further sensor information (Janevic and Connell, 2019). Critically, interventions based on sound BCT theory have been shown to be more effective for behaviour change than those not informed by theory (Glanz and Bishop, 2010; Wang et al., 2019). However, such foundations are currently focussed on immediate behaviour change and lack concern for long-term behaviour change. 
One difficulty with behavioural theories and currently existing models is that they offer little guidance on how to operationalise or translate the knowledge about human behaviour (and change techniques) into specific solutions (Wang et al., 2019). The role of technology and the relationship with the actual intervention often remain vague. Designers that aim to change people's behaviours and habits have to assess whether their solutions actually work and bring about the desired behaviour. It is, however, difficult to unambiguously prove or demonstrate whether and how an implemented technology contributes to a changed behaviour (Klasnja et al., 2011) compared to other factors such as life changes (Rapp et al., 2019). Little is known about how intrinsic properties of certain technologies are related to specific behavioural change techniques. Additionally, most interventions rely on a combination of BCTs and other behaviour change strategies. That is, different solutions and subsystems are integrated in an intervention system. This is complicated by the fact that behaviour change is a long-term and complex process involving a plethora of, often emergent, factors. Further, long-term behaviour change is strongly connected to the time period a person has maintained a certain target behaviour (Klasnja et al., 2011). In smoking cessation, e.g., approx. 7\% of people relapse after five years of abstinence compared to $47 \%$ of people who had stopped smoking for a year. Thus, further work is required to analyse the mechanisms and most important factors underpinning sustained behaviour change. Given these needs, this work sets out to

- Explore emerging trends and common characteristics of immersive technologies in three fields (human computer interaction (HCI), human robot interaction (HRI) and game design (GD)).

- Elucidate how BCTs relate to technology in technology-enabled interventions for sustained behaviour change.

- Examine which of the BCTs are particularly affected or disrupted by key characteristics of interactive immersive technologies.

Bringing these elements together, it is possible to form an initial conceptual framework relating BCTs relevant to long-term behaviour change and the various characteristics of relevant technologies. This framing requires to abstractly define both the fundamental characteristics of BCTs and technology so that an assessment of their interaction and relationship can be made. For the former, we draw on the widely accepted BCTT framework (Michie et al., 2013). For the latter, two established models are relevant: the Technology Acceptance Model (TAM) and the Unified Theory of Acceptance and Use of Technology (UTAUT) (Davis, 1989; Venkatesh et al., 2003). TAM offers three constructs - perceived ease of use, perceived usefulness, attitude towards use - that determine the adoption of a technology from a user perspective, while the UTAUT includes factors such as social influence, facilitating conditions, effort expectancy and performance expectancy. By contrasting the BCTs against technologies described in terms of TAM/UTAUT, we are able to describe key relationships between the behaviour change clusters and underlying technological characteristics.

\section{METHOD}

In order to answer the research question, a literature review was conducted. A literature review, is well suited to obtaining an overview of an emerging research area (Snyder, 2019), such as immersive technology trends in HCI, HRI, and GD. The criteria for including papers and articles in the review sample was relevance based on the articles' keywords, titles and abstracts, and publication date. Only articles published from 2014 onwards were included due to the focus on emerging trends. The articles were found on the electronic databases and platforms Google Scholar, Scopus, and ResearchGate. Related keywords include combinations of the following: "Trends" OR "Developments" OR "Emergent technologies" OR "Emergent trends" OR "New technologies" OR "Disruption" OR "Advanced technologies") AND ("HCI" OR "HRI" OR "GD" OR "Human computer interaction" OR "Human robot interaction")

Data has been collected from circa 50 research papers as well as from 30 other technical articles. The full text of the selected articles was read and information was extracted for the following criteria. Qualitative criteria included explanations of technology trend(s), potential impacts of the specific technology trend(s), and the level of expertise of the publishing authors.

Based on this method and the generated data, a qualitative thematic analysis was performed. Three major steps were conducted in this process. First, we identified key developments in HCI, HRI and GD in an open coding process. This resulted in the recognition of 11 technological trends and served as the first level data on the overview of immersive technology trends. Second, these 11 trends and 
clusters were confirmed by one expert interviewee who has extensive experience and expertise in HCI and HRI. Third, we contrasted the Behaviour Change Technique clusters against the proposed trends via axial coding. This led to second level data on the relationships and interactions between both fields and resulted in the formulation of three technology themes in behaviour change interventions.

\section{RESULTS}

This section illustrates the disruptive potential of immersive technologies for sustained behaviour change. First, current trends of interactive immersive technologies in HCI and HRI and game design and development are introduced. Then, shared features and common fundamental mechanisms of the selected technologies are identified. This is followed by an investigation of the underlying properties of the individual BCT clusters. A selection of four BCT clusters that appear particularly likely to be affected by changes in technology are then highlighted. Lastly, the role of technology in interventions is discussed and directly connected to the BCT clusters. Overall, three main thematic roles of technologies are derived: technology as a conveyor of information, as an augmenter of feedback, and as an embodiment of empathy.

\subsection{Overview of interactive immersive technologies trends}

The data presented 11 main trends ranging from Virtual Reality (VR) to interactive storytelling powered by Artificial Intelligence (AI). Collectively these represent different artefacts, manifestations and (components of) systems of technology-enabled interventions. Table 1 introduces the identified interaction technology trends and their explanations. This is complemented by a presentation of the most important technological mechanisms that are embodied by the identified technologies.

\subsection{Disruptive potential of interactive immersive technologies for sustained behaviour change}

This section focuses on the presentation of three themes in the disruptive potential of immersive technologies for sustained behaviour change. The themes have been obtained by contrasting the immersive technology trends of Section 4.1 with the BCT clusters. This evaluation of the impact on the BCT clusters is based on the qualitative assessment of the inherent qualities and characteristics of the respective BCT cluster (e.g. some behaviour change techniques belonging to one cluster are of static nature) and the underlying mechanisms embodied by technologies (e.g. vividness, immersion ...).

Table 1: Overview of the Technology themes, Conveyor of Information (1), Augmenter of

Feedback (2), Embodiment of Empathy (3), and identified emerging technology trends.

Hardware-related, software-related, as well as social trends are indicated by blue, orange, and green squares respectively.

\begin{tabular}{|c|c|c|}
\hline Technology & $\begin{array}{l}\text { Technological mechanisms Technology } \\
\text { acceptance model and the unified theory of } \\
\text { acceptance and use of technology }\end{array}$ & $\begin{array}{c}\text { Themes } \\
\text { \& } \\
\text { Trends }\end{array}$ \\
\hline \multirow{2}{*}{$\begin{array}{l}\text { Virtual Reality (VR) is a "[...] very high- } \\
\text { end computer interface that evolves real } \\
\text { time simulation and interface through } \\
\text { numerous sensorial channels. These } \\
\text { sensorial modalities are visual, aural, } \\
\text { tangible, smell, taste and other senses" } \\
\text { (Kundalakesi et al., 2017, p. } 374) \text {. }\end{array}$} & \multirow{2}{*}{$\begin{array}{l}\text { Vividness; Interactivity; Dynamism; } \\
\text { Ability for quick intervention; Real-time } \\
\text { feedback; Connectivity; } \\
\text { Portability/Mobility; Presence; Immersion; } \\
\text { Personalisation; Accessibility; Context } \\
\text { sensitivity; Responsiveness; Adaptability }\end{array}$} & $1,2,3$ \\
\hline & & \\
\hline \multirow{2}{*}{$\begin{array}{l}\text { "Augmented Reality (AR) technology is a } \\
\text { technology that combines virtual } \\
\text { information with the real world. The } \\
\text { technical means it uses include } \\
\text { Multimedia, 3D-Modelling, Real-time } \\
\text { Tracking and Registration, Intelligent } \\
\text { Interaction, Sensing and more" (Chen et } \\
\text { al., 2019, p. 1). }\end{array}$} & \multirow{2}{*}{$\begin{array}{l}\text { Vividness; Interactivity; Dynamism; } \\
\text { Ability for quick intervention; Real-time } \\
\text { feedback; Augmentation and enhancement } \\
\text { of reality; Connectivity; } \\
\text { Portability/Mobility; Immersion; } \\
\text { Personalisation; Accessibility; Context } \\
\text { sensitivity; Responsiveness; Adaptability }\end{array}$} & $1,2,3$ \\
\hline & & \\
\hline
\end{tabular}




\begin{tabular}{|c|c|c|}
\hline $\begin{array}{l}\text { "A Chatbot is a computerized program } \\
\text { that acts like a colloquist between the } \\
\text { human and the bot, a virtual assistant that } \\
\text { has become exceptionally popular in } \\
\text { recent years mainly due to dramatic } \\
\text { improvements in the areas like artificial } \\
\text { intelligence, machine learning and other } \\
\text { underlying technologies such as neural } \\
\text { networks and natural language } \\
\text { processing" (Gupta et al., 2020, p. 255). }\end{array}$ & $\begin{array}{l}\text { Vividness; Interactivity; Dynamism; } \\
\text { Ability for quick intervention; Real-time } \\
\text { feedback; Augmentation and enhancement } \\
\text { of reality; Connectivity; Personalisation; } \\
\text { Context sensitivity; Responsiveness; } \\
\text { Adaptability }\end{array}$ & $1,2,3$ \\
\hline $\begin{array}{l}\text { "The digital twin is a comprehensive } \\
\text { digital representation of an individual } \\
\text { product. It includes the properties, } \\
\text { condition and behaviour of the real-life } \\
\text { object through models and data. The } \\
\text { digital twin is a set of realistic models that } \\
\text { can simulate its actual behaviour in the } \\
\text { deployed environment" (Haag and Anderl, } \\
\text { 2018, p. 64). }\end{array}$ & $\begin{array}{l}\text { Interactivity; Dynamism; Ability for quick } \\
\text { intervention; Real-time feedback; } \\
\text { Augmentation and enhancement of reality; } \\
\text { Connectivity; Presence; Personalisation; } \\
\text { Context sensitivity; Responsiveness; } \\
\text { Adaptability }\end{array}$ & 1,2 \\
\hline $\begin{array}{l}\text { Avatars are any type of representation that } \\
\text { marks a person's entity (Ahn et al., 2012). } \\
\text { In fact, "[...] avatars have become more } \\
\text { complex creations, rendered in three- } \\
\text { dimensional forms with an extensive range } \\
\text { of animated movements that aid in the } \\
\text { expression of the avatar's personality and } \\
\text { supplement various social interactions" } \\
\text { (Ahn et al., 2012, p. 697). An avatar serves } \\
\text { as a "digital representation that symbolizes } \\
\text { the self in the interaction" (Nowak and } \\
\text { Fox, 2018, p. 32). }\end{array}$ & $\begin{array}{l}\text { Vividness; Interactivity; Dynamism; Real- } \\
\text { time feedback; Augmentation and } \\
\text { enhancement of reality; Connectivity; } \\
\text { Presence; } \\
\text { Personalization; Context sensitivity; } \\
\text { Responsiveness; } \\
\text { Adaptability }\end{array}$ & $1,2,3$ \\
\hline $\begin{array}{l}\text { Wearable technology is "[...] an } \\
\text { application-enabled computing device } \\
\text { which accepts and processes inputs. This } \\
\text { device is generally a fashion accessory } \\
\text { usually worn or attached to the body. The } \\
\text { device could work independently or be } \\
\text { tethered to a smartphone allowing some } \\
\text { kind of meaningful interaction with the } \\
\text { user. The wearable product could be on } \\
\text { the body (like a smart patch), around the } \\
\text { body (like a wristwatch or a headband) or } \\
\text { in the body (like an identification sensor } \\
\text { embedded under the skin or a sensor } \\
\text { attached to the heart monitoring } \\
\text { cardiac aberrations)" (Cicek, 2015, p. 46). }\end{array}$ & $\begin{array}{l}\text { Vividness; Interactivity; Dynamism; } \\
\text { Ability for quick intervention; Real-time } \\
\text { feedback; Augmentation and enhancement } \\
\text { of reality; Connectivity; } \\
\text { Portability/Mobility; Personalisation; } \\
\text { Accessibility; Context sensitivity; } \\
\text { Responsiveness; Adaptability }\end{array}$ & $1,2,3$ \\
\hline $\begin{array}{l}\text { "Speech Recognition (SRS) is the process } \\
\text { of extracting the string of words } \\
\text { automatically from the speech signal by } \\
\text { means of an algorithm. It is the ability of a } \\
\text { machine or program to identify words and } \\
\text { phrases in spoken language and convert } \\
\text { them to a machine- readable format" } \\
\text { (Mehmood and Saqib, 2014, p. 1). }\end{array}$ & $\begin{array}{l}\text { Interactivity; Dynamism; Real-time } \\
\text { feedback; Connectivity; } \\
\text { Portability/Mobility; Personalisation; } \\
\text { Accessibility; Context sensitivity; } \\
\text { Responsiveness; } \\
\text { Adaptability }\end{array}$ & 2,3 \\
\hline
\end{tabular}




\begin{tabular}{|l|l|c|}
\hline Interactive storytelling powered by & Vividness; Interactivity; Dynamism; & 3 \\
Artificial intelligence (AI) refers to "[...] & Connectivity; Personalisation; Context & \\
AI techniques that control either plot & sensitivity; Responsiveness; & \\
generation or real-time character & Adaptability & \\
behaviour" (Cavazza et al., 2003, p. 1). & & \\
\hline
\end{tabular}

\subsubsection{Technology theme 1: Technology as a conveyor of information}

The identified immersive technology trends enable new dimensions in connectivity, adaptability, context sensitivity, personalisation, enhancement of reality, the ability for quick intervention as well as vividness. Thus, these added layers and functionalities are likely to go beyond current limitations of how information is conveyed and addressed by BCTs. Designers can exploit the mentioned technological capabilities and enhance the user's perception capabilities through real-time data provision, increase the degree of customisation of messages delivered in a more multimodal interactive way, and predict and visualise more vividly the future impact of one's behaviour. Vividness, i.e. the degree of richness of representations of an environment and how an environment presents information to a person's senses (Steuer, 1992) can be increased by the incorporation of more modalities used to appeal to different senses (Nicholson et al., 2008). For a successful and engaging conveying of information, technology tools need to be adaptable to their circumstances, user requirements as well as situations. The ability to customise messages depending on current and changing situations is important for personalisation. Making people familiar with the likely consequences - positive and negative - of a specific behaviour or lifestyle is a powerful enabler that can lead to behaviour change (BEHAVE, n.d.). In a VR study, participants of one group perform tasks while being confronted with themselves as aged reflections in a mirror (Ersner-Hershfield, H., Bailenson, J., \& Carstensen, 2008). The people of the second group are shown avatars of their current age. Participants of the first group have been shown to save significantly more money for retirement than those from the second group. Due to these technological characteristics, it is likely that BCT cluster 7 (natural consequences) will be substantially affected. In particular, increase in personalisation, vivid messages, and adaptable connected devices and displays are likely to change how information has been conveyed previously and thus behaviour change strategies.

\subsubsection{Technology theme 2: Technology as an augmenter of feedback}

This theme refers to developments in providing interactive feedback and monitoring. Technology can be utilised as an augmenter and facilitator of feedback. Relevant underlying technology characteristics of theme 2 include e.g. real-time feedback, dynamism, responsiveness, and interactivity. For example, AR/VR are reinventing the way feedback on desired behaviours is given. The absence of feedback, delayed or scarce feedback often causes people to abandon a behaviour (Dirksen et al., 2019). Accurate and timely feedback should therefore play an integral part in interventions. AR/VR feedback in response to a person's behaviour can be given through audio-visual content, visualisations, 3D instructions, haptic feedback, or other stimuli (Petsani et al., 2018). Health games - "a subgenre within serious games that denotes the use of games designed to inform and improve health" - are promising applications for AR and VR (Egenfeldt-Nielsen et al., 2019, p. 326). For instance, combining the incorporation of gamification of rehabilitation regimes with immersive technology could increase the adherence and enjoyment of the therapy. Games in general have been proven to heighten the capacity for learning and increase creativity of players (Egenfeldt-Nielsen et al., 2019). Quests are characterised as "[...] missions in a game that help to structure action for the user or player" (Egenfeldt-Nielsen et al., 2019, p. 44). Especially patients with serious impairments might benefit from a separation from their daily life and diseases. Consequently, this could contribute to a feeling of empowerment and a sense of agency. Further, activity tracking devices are highly efficient instruments for self-monitoring. Users are motivated for achieving pre-set objectives and goals through reward systems e.g. congratulatory messages or vibrational feedback. Fitness trackers such as Fitbit Flex 2, Moov Now, and Misfit Shine 2 possess self-evaluation features. For example, current statistics and exercise results are presented. Discrepancies between the desired behavioural goal and the current behaviour are visualised with the help of progress bars or bar charts. (Cheng Chia et al., 2019). It is likely that BCT clusters 8 (feedback and monitoring) and 9 (goals and planning) will be most disrupted. The features real-time feedback and interactivity are directly related to cluster 8 and 
extending classical behaviour change techniques for giving feedback. Goal setting and measuring progress are drastically changed by these technologies.

\subsubsection{Technology theme 3: Technology as an embodiment of empathy}

Emerging technologies go beyond the mere compliance with a solution and new technological advances allow people to have a virtual "social companion". Consequently, technology is adopting a role of an embodiment of empathy. This requires key technological characteristics such as accessibility, connectivity, interactivity, dynamism, and adaptability. Embodiments span from novel ways to animate or encourage certain targeted behaviours, sharing common experiences, to literally seeing the world from another person's perspective. Immersive technologies can increase empathy and allow people to walk in another's shoes (Dirksen et al., 2019). Empathy is a means of maintaining good and improving relationships. One example is that empathy in healthcare can result in an enhanced patient experience, better patient care and a reduction of anxiety among patients before a surgery. This requires the clinician or healthcare provider to deeply understand the problems, pains, and fears of the patient (Dirksen et al., 2019). BeAnotherLab created a body swapping system which aims to create the illusion of being in another person's body. The system uses a head-mounted display and incorporates visual, tactile, and audio signals (De Oliveira et al., 2016). It can also include storytelling as an additional component to enhance the empathy effect. The person views the world from the perspective of the second person imitating the first person's movements. Here, BCT cluster 10 (social support) is most affected. Chatbots, VR body swaps and social groups on wearable activity trackers are changing how social and emotional support is provided. In behavioural design and interventions, the interactive and dynamic nature of those technologies are likely to result in unprecedented social support for the performance of behaviours.

\section{DIscussion}

The starting point for this work was a lack of guidance in how knowledge about human behaviour and behavioural strategies can be operationalised for the actual design of an intervention (Wang et al., 2019). We have illustrated how emerging technologies have the potential to enable new approaches to design for (sustained) behaviour change. That is, to exploit these new degrees of freedom, designers must first be aware of the novel possibilities in the context of behaviour change. Recent literature emphasises the difficulty in assessing how an implemented technology leads to a desired behaviour change. Even though the TAM and the UTAUT models are well established from a user perspective, they are not applicable for this specific task. Therefore, a deeper analysis of the underlying properties and the distinct technological characteristics has been presented that goes beyond the two models. The mapping of the identified set of technologies and its characteristics to the BCTT framework reveals and showcases the potential of immersive technologies for behaviour change. Instead of simply being a transmitter or facilitator, technology has been found to have three further important themes: conveying information, augmenting feedback and serving as an embodiment of empathy. Not every immersive technology possesses all identified technological characteristics. Nonetheless, new insights are gained regarding the BCT-intervention relationship. In particular, we highlight substantial potential related to four BCT clusters (natural consequences, feedback and monitoring, goals and planning, and social support). This directly relates to a mitigation of one of the current pain points in behavioural design concerning the difficulty to unambiguously demonstrate how a specific technology contributes to behaviour change (Klasnja et al., 2011). However, the prediction of future effects of technological advances on behavioural change strategies is a new proposition to the field of behavioural design and requires further investigation. Figure 1 illustrates the interactions between BCTs and technologies, based on the themes. Future work could follow-up on the foundation laid out here to further expand upon identified technology themes and ties to BCTs, investigate case examples also from industry practice, additionally explore different angles to behaviour change, and provide design guidance toward implementation.

\section{LIMITATIONS}

Before evaluating the implications of this work, two main limitations have to be considered. First, the results are limited to the available scope and search string of the literature review. There are naturally more than 11 technology trends in HCI, HRI, and GD. Consequently, more specific or distantly related technological characteristics require further work to explore. Nonetheless, the literature review is an important first step as there is a lack of prior research especially regarding the relationship between 
BCTs and emerging technologies. Second, there is a lack of temporality in the BCTT framework. This element is, however, crucial for the design of solutions for long-term behavioural change. People are required to maintain a target behaviour over the period of several years to achieve a lasting behaviour change (Klasnja et al., 2011; Prochaska et al., 1998). In rehabilitation, e.g., a linear process with only one intervention does not properly reflect the real recovery process. It is likely that the behaviour drifts and that maintaining sustained behaviour change (e.g. adherence to daily exercises, cardio program, mental workouts, medication plans) is a key challenge. Kwasnicka et. al. (2016) emphasise that intervention effects diminish over time. In rehabilitation of stroke patients, e.g., this might necessitate further external interventions or self-correction mechanisms. Despite that, this work lays the groundwork for a future in-depth analysis of long-term behaviour change and its factors. Little is known and little empirical research has been conducted in this area of design. Thus, further work is needed to analyse the underpinning mechanisms and principles of design for long-term adherence.

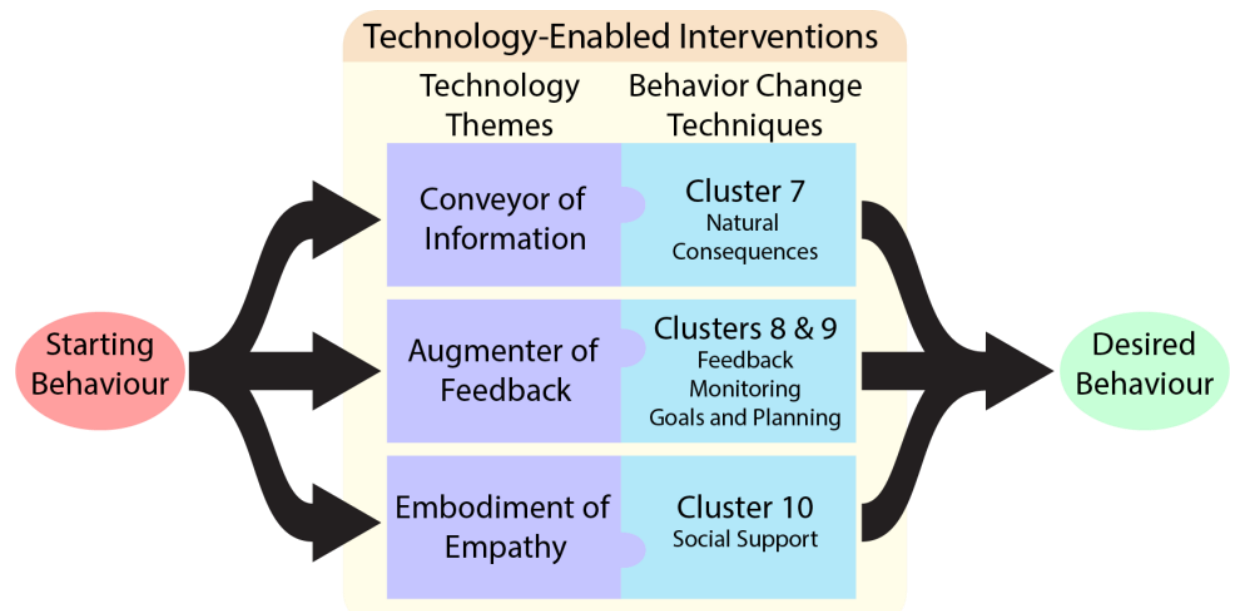

Figure 1: illustration of extended theme of technology in technology-enabled behaviour change interventions. Mapping technology themes (this paper) with clusters of behaviour change techniques (bcts) with focus on the effect on the behaviour change technique taxonomy (bctt) framework.

\section{IMPLICATIONS}

In terms of design theory, this work explores a connection between previously separated elements: BCTs and technological interventions. We investigate the impact of emergent technologies (and more importantly their underlying mechanisms) on the delivery of behaviour change techniques and interventions, emphasising four main BCT clusters.

In terms of design practice, we propose three important thematic roles of emerging immersive technology that extend the classification of technology given by Kelders et al. (2012): Technology can convey information, augment feedback, and embody empathy. While this exploration is not exhaustive, it could provide designers with directions when examining the suitability of different technologies for interventions based on the required solution properties (e.g. vividness, interactivity, adaptability etc.).

\section{CONCLUSION}

In this work, we set out to answer the research question: What is the relationship between Behaviour Change Techniques and interactive immersive technologies with respect to sustaining behaviour over the longer term? To this end, we conducted a literature review on emerging technology trends in the fields of human computer interaction, human robot interaction, and game design. Based on our results, we proposition three main contributions. First, we propose a number of technological characteristics and mechanisms in emerging immersive technologies. Second, we highlight a number of technology themes connected to specific BCT clusters, which are likely to be disrupted: technology as conveyor of information, as augmenter of feedback, and as an embodiment of empathy (Figure 1). Third, we explore these connections between BCT clusters and the actual technological interventions. However, achieving sustained behaviour change typically includes multiple lapses, setbacks, and intervention designs with a non-linear behaviour change process. Thus, further work is needed to investigate the underpinning mechanisms, factors, and principles of adherence for sustained behavioural change. 


\section{ACKNOWLEDGMENTS}

This work has received funding from the Horizon 2020 research and innovation programme of the European Union under grant agreement no. 871767 of the project ReHyb: Rehabilitation based on hybrid neuroprosthesis.

\section{REFERENCES}

Ahn, S.J., Fox, J. and Bailenson, J.N. (2012), “Avatars”, in Bainbridge, W.S. (Ed.), Leadership in Science and Technology: A Reference Handbook, SAGE Publications, Inc.

BEHAVE. (n.d.). "Behavior Depends on Consequences", Behavioural Principles and Practices, No. 1.1.1.

Bohlen, L.C., Michie, S., de Bruin, M., Rothman, A.J., Kelly, M.P., Groarke, H.N.K., Carey, R.N., et al. (2020), "Do Combinations of Behavior Change Techniques That Occur Frequently in Interventions Reflect Underlying Theory?", Annals of Behavioral Medicine, Vol. 54 No. 11, pp. 827-842.

Cash, P., Khadilkar, P., Jensen, J., Dusterdich, C. and Mugge, R. (2020), "Designing behaviour change: A behavioural problem/solution (BPS) matrix", International Journal of Design, Vol. 14 No. 2, pp. 65-83.

Cash, P.J., Hartlev, C.G. and Durazo, C.B. (2017), "Behavioural design: A process for integrating behaviour change and design", Design Studies, Vol. 48, pp. 96-128.

Cavazza, M., Charles, F. and Mead, S.J. (2003), "Interactive Storytelling : From Ai Experiment To New Media", Proceedings of the International Conference on Entertainment Computing (ICEC'03), pp. 1-8.

Chen, Y., Wang, Q., Chen, H., Song, X., Tang, H. and Tian, M. (2019), "An overview of augmented reality technology", Journal of Physics: Conference Series, Vol. 1237 No. 2,.

Cheng Chia, G.L., Anderson, A. and McLean, L.A. (2019), "Behavior change techniques incorporated in fitness trackers: Content analysis", JMIR MHealth and UHealth, Vol. 7 No. 7, https://doi.org/10.2196/12768.

Cicek, M. (2015), "Wearable Technologies And Its Future Applications", International Journal of Electrical, Electronics and Data Communication, Vol. 3 No. 4, pp. 45-50.

Davis, F.D. (1989), "Perceived usefulness, perceived ease of use, and user acceptance of information technology", MIS Quarterly: Management Information Systems, Vol. 13 No. 3, pp. 319-340.

Dirksen, J., DiTommaso, D. and Plunkett, C. (2019), "Augmented and Virtual Reality for Behavior Change", The ELearning Guild.

Egenfeldt-Nielsen, S., Smith, J.H. and Tosca, S.P. (2019), Understanding Video Games: The Essential Introduction, Routledge.

Ersner-Hershfield, H., Bailenson, J., \& Carstensen, L.. (2008), "Feeling more connected to your future self", Association for Psychological Science Annual Convention, Chicago, IL.

Fogg, B. (2009a), "Creating persuasive technologies", Persuasive '09: Proceedings of the 4th International Conference on Persuasive Technology, pp. 1-6.

Fogg, B. (2009b), "A behavior model for persuasive design", ACM International Conference Proceeding Series,

Fogg, B.J. and Hreha, J. (2010), "Behavior Wizard: A Method for Matching Target Behaviors with Solutions", PERSUASIVE 2010: Persuasive Technology, pp. 117-131.

Glanz, K. and Bishop, D.B. (2010), "The role of behavioral science theory in development and implementation of public health interventions", Annual Review of Public Health, Vol. 31, pp. 399-418.

Gupta, A., Hathwar, D. and Vijayakumar, A. (2020), "Introduction to AI Chatbots", International Journal of Engineering Research and Technology, Vol. 9 No. 7, pp. 255-258.

Haag, S. and Anderl, R. (2018), "Digital twin - Proof of concept", Manufacturing Letters, pp. 64-66.

Halaweh, M. (2013), "Emerging technology: What is it?", Journal of Technology Management and Innovation, Vol. 8 No. 3, https://doi.org/10.4067/s0718-27242013000400010.

Janevic, M.R. and Connell, C.M. (2019), "Individual Theories", in Hilliard, M.E., Riekert, K.A., Ockene, J.K. and Pbert, L. (Eds.), The Handbook of Health Behavior Change, 5th ed., Springer Publishing Company,

Kelders, S.M., Kok, R.N., Ossebaard, H.C. and Van Gemert-Pijnen, J.E.W.C. (2012), "Persuasive system design does matter: A systematic review of adherence to web-based interventions", Journal of Medical Internet Research, Vol. 14 No. 6, https://doi.org/10.2196/jmir.2104.

Khadilkar, P.R. and Cash, P. (2020), "Understanding behavioural design: barriers and enablers", Journal of Engineering Design, pp. 1-22.

Klasnja, P., Consolvo, S. and Pratt, W. (2011), "How to evaluate technologies for health behavior change in HCI research", Conference on Human Factors in Computing Systems - Proceedings, https://doi.org/10.1145/1978942.1979396.

Kundalakesi, M., Swathi, T., Ashapriya, B. and Sruthi, R. (2017), “A Study of Virtual Reality”, International Journal of Trend in Research and Development, Vol. 4 No. 3, pp. 374-377.

Kwasnicka, D., Dombrowski, S.U., White, M. and Sniehotta, F. (2016), "Theoretical explanations for maintenance of behaviour change: a systematic review of behaviour theories", Health Psychology Review, Vol. 10 No. 3, pp. 277-296. 
Mehmood, F. and Saqib, K. (2014), “An Overview on Speech Recognition System and Comparative Study of its Approaches”, International Conference on Engineering \& Emerging Technologies (ICEET-2014), University, Superior, Lahore.

Michie, S., Atkins, L. and West, R. (2014), The Behaviour Change Wheel: A Guide to Designing Interventions, The Behavior Change Wheel: Book Launch Event.

Michie, S., Richardson, M., Johnston, M., Abraham, C., Francis, J., Hardeman, W., Eccles, M.P., et al. (2013), "The behavior change technique taxonomy (v1) of 93 hierarchically clustered techniques: Building an international consensus for the reporting of behavior change interventions", Annals of Behavioral Medicine, Vol. 46 No. 1, pp. 81-95.

Milgram, P. and Kishino, F. (1994), "Taxonomy of mixed reality visual displays”, IEICE Transactions on Information and Systems, pp. 1321-1329.

Naslund, J.A., Aschbrenner, K.A., Kim, S.J., McHugo, G.J., Unützer, J., Bartels, S.J. and Marsch, L.A. (2017), "Health behavior models for informing digital technology interventions for individuals with mental illness.", Psychiatric Rehabilitation Journal, Vol. 40 No. 3, pp. 325-335.

Nicholson, J., B Nicholson, D. and S. Valacich, J. (2008), "Examining the Effects of Technology Attributes on Learning: A Contingency Perspective”, Journal of Information Technology Education: Research, Vol. 7, pp. 185-204.

Nowak, K.L. and Fox, J. (2018), “Avatars and computer-mediated communication: A review of the definitions, uses, and effects of digital representations", Review of Communication Research, Vol. 6, pp. 30-53.

De Oliveira, E.C., Bertrand, P., Lesur, M.E.R., Palomo, P., Demarzo, M., Cebolla, A., Banos, R., et al. (2016), "Virtual Body Swap: A New Feasible Tool to Be Explored in Health and Education", Proceedings - 18th Symposium on Virtual and Augmented Reality, SVR 2016, pp. 1-9.

Pavithra, A. (2020), “An Emerging Immersive Technology-A Survey”, Ijirt, Vol. 6 No. 8, pp. 119-130.

Petsani, D., Kostantinidis, E.I. and Bamidis, P.D. (2018), "Designing an E-coaching system for older people to increase adherence to exergame-based physical activity", ICT4AWE 2018 - Proceedings of the 4th International Conference on Information and Communication Technologies for Ageing Well and e-Health

Prochaska, J.O., Johnson, S. and Lee, P. (1998), "The transtheoretical model of behavoir change", in Shumaker, S.A., Schron, E.B., Ockene, J.K. and McBee, W.L., Handbook of Health Behavior Change, pp. 59-84.

Rapp, A., Tirassa, M., \& Tirabeni, L. (2019). Rethinking technologies for behavior change: A view from the inside of Human change. ACM Transactions on Computer-Human Interaction, 26(4).

Shih, J.J., Krusienski, D.J. and Wolpaw, J.R. (2012), “Brain-computer interfaces in medicine”, Mayo Clinic Proceedings, Vol. 87 No. 3, pp. 268-279.

Snyder, H. (2019), "Literature review as a research methodology: An overview and guidelines", Journal of Business Research, Vol. 104, pp. 333-339.

Sony, M. and Mekoth, N. (2018), “A qualitative study on electricity energy-saving behaviour”, Management of Environmental Quality: An International Journal, Vol. 29 No. 5,

Steuer, J. (1992), "Defining Virtual Reality: Dimensions Determining Telepresence”, Journal of Communication, Vol. 42 No. 4, pp. 73-83.

Thorpe, J.R., Forchhammer, B.H. and Maier, A.M. (2019), "Development of a sensor-based behavioral monitoring solution to support dementia care", Journal of Medical Internet Research, Vol. 7 No. 6, https://doi.org/10.2196/12013.

Thorpe, J.R., Rønn-Andersen, K.V.H., Bień, P., Özkil, A.G., Forchhammer, B.H. and Maier, A.M. (2016), "Pervasive assistive technology for people with dementia: A UCD case", Healthcare Technology Letters, Vol. 3 No. 4, pp. 297-302.

Venkatesh, V., Morris, M.G., Davis, G.B. and Davis, F.D. (2003), "User acceptance of information technology: Toward a unified view”, MIS Quarterly: Management Information Systems, Vol. 27 No. 3, pp. 425-478.

Wang, Y., Fadhil, A., Lange, J.P. and Reiterer, H. (2019), "Integrating taxonomies into theory-based digital health interventions for behavior change: A holistic framework", Journal of Medical Internet Research, Vol. 8 No. 1, https://doi.org/10.2196/resprot.8055.

Yao, M., Chen, J., Jing, J., Sheng, H., Tan, X. and Jin, J. (2017), "Defining the rehabilitation adherence curve and adherence phases of stroke patients: An observational study", Patient Preference and Adherence, Vol. 11, pp. 1435-1441. 